\title{
Policy Analysis on Establishing Criteria for Population versus Individual-based Health Services towards Achieving Universal Health Care
}

\author{
Leonardo R. Estacio Jr., MCD, MPH, PhD,1,2 Ma-Ann M. Zarsuelo, RND, MSc, ${ }^{1,3}$ \\ Christine Mae S. Avila, MD, ${ }^{1}$ Ma. Esmeralda C. Silva, MPAf, MSPPM, PhD, ${ }^{1,4}$ \\ Michael Antonio F. Mendoza, DDM, MA ${ }^{1,5}$ and Carmencita D. Padilla, MD, MAHPS 6 \\ ${ }^{1}$ University of the Philippines Manila Health Policy Development Hub \\ ${ }^{2}$ College of Arts and Sciences, University of the Philippines Manila \\ ${ }^{3}$ Institute of Health Policy and Development Studies, National Institutes of Health, University of the Philippines Manila \\ ${ }^{4}$ College of Public Health, University of the Philippines Manila \\ ${ }^{5}$ College of Dentistry, University of the Philippines Manila \\ ${ }^{6}$ University of the Philippines Manila
}

\begin{abstract}
Background. The enactment of the Universal Health Care Act is anticipated to bring wider coverage and accessibility of quality healthcare services as stipulated in its objectives. With the integration of the healthcare system at the provincial level, determining population- and individual-based services is crucial in mapping the managerial and financial roles. Hence, this study aimed to establish the criteria for identifying population-based and individualbased health services in the Philippines.
\end{abstract}

Methods. A systematic review of literature was conducted to generate evidence for the policy brief and discussion points on the roundtable discussion spearheaded by the UP Manila Health Policy Development Hub in collaboration with the Department of Health. Key stakeholders of the policy issue convened to share expertise and insights in determining criteria for population- and individual-based services, intending to generate consensus policy recommendations.

Results. The general scope of individual-based health services stipulated in the Law are to be financed under the benefit packages of PHIC and HMOs. Meanwhile, population-based services are those that address public health issues such as health promotion and disease surveillance. Several services considered as 'grey areas' are those that fall in the overlap of the individual- and population-based services. These services may be examined through an outcome-based algorithm that examines fragmentation issues both in the supply and demand side of service delivery.

Conclusion and Recommendation. Proposed criteria in identifying individual- and population-based services include the number of recipient/s, the effectivity of service delivery and utilization, and source of funding. Health programs that are in the grey areas can be examined through an outcome-based algorithm.

Key Words: Healthcare Financing, Delivery of Health Care, Health Services Accessibility

\section{INTRODUCTION}

Corresponding author: Ma-Ann M. Zarsuelo, RND, MSc UP Manila Health Policy Development Hub

National Institutes of Health

University of the Philippines Manila

623 Pedro Gil St., Ermita, Manila 1000, Philippines

Email: mmzarsuelo@up.edu.ph
The enactment of the Universal Health Care (UHC) Act supports the right of every Filipino to have access to preventive, promotive, curative, rehabilitative, and palliative health services while providing maximal and equitable financial protection to the whole population. The provisions of the law differentiate individual-based from populationbased services and subsequently delineate financial roles to 
the Department of Health, the Local Government Units (LGUs), and Philippine Health Insurance Corporation. ${ }^{1}$

Section $4(\mathrm{p})$ of the Law states that individual-based health services "refer to services which can be accessed within a health facility or remotely that can be definitively traced back to one recipient, has a limited effect at a population level, and does not alter the underlying cause of illness, such as ambulatory and inpatient care, medicines, laboratory tests, and procedures, among others." Population-based health services, on the other hand, refer to "interventions such as health promotion, disease surveillance, and vector control, which have population groups as recipients." ${ }^{1}$ Furthermore, Section 6 stipulates the service coverage wherein (a) "every Filipino shall be granted immediate eligibility and access to preventive, promotive, curative, rehabilitative, and palliative care for health services, delivered either as population-based or individual-based;" and (b) "PhilHealth shall implement a comprehensive outpatient benefit, including outpatient drug benefit and emergency medical services under the recommendations of the Health Technology Assessment..." This is complemented by (c) "the DOH and the LGUs that shall endeavor to provide health care delivery system that will afford every Filipino a primary care provider that would act as the navigator, coordinator, and initial and continuing point of contact in the health care delivery system" and that (d) "every Filipino shall register with a public or private primary care provider of choice" with $\mathrm{DOH}$ promulgating guidelines for licensing service providers. ${ }^{1}$

Identifying health interventions as population-based or individual-based is fundamental in delegating responsibilities and establishing financing roles of respective agencies for the implementation of the UHC Act.

Population-based interventions shall pertain to services that aim to improve the health of the population or the public rather than of individuals. By objectives, these services shall promote wellness and primary prevention of diseases. Hence, it should address the multiple determinants of health (e.g. social, political and ecological factors, etc.), especially catering to the needs of local communities and addressing health disparities in vulnerable and marginalized population groups. Given the extent of coverage, long-term outcomes of populationbased interventions shall be to reduce healthcare demands and contribute to the sustainability of the health system. ${ }^{2}$

Population-based health strategies that target wellness and prevention of illness may have significant potential gains but the effect on each individual per se may not be as significant. ${ }^{3}$ Thus, individual-based health strategies or interventions are necessary to address the needs of an individual in a personal, clinical, or health facilitybased level. ${ }^{3}$ Health service utilization of an individual is commonly linked to socio-cultural, religious, and personal beliefs. By the virtue of estimating gains, individual-based health interventions focus more on services that shall highly motivate and benefit a person (i.e. favorable benefit-risk ratio $)^{3}$ or are demand-driven. It may also include extensive screening processes to identify high-risk individuals (e.g. for communicable and non-communicable diseases) which may necessitate high medical costs and specialized care. Further, these interventions are more on temporary medical care, cure, rehabilitation, and palliation ${ }^{3}$.

The relationship between population and individual health is partially based on the dichotomization of medicine into clinical medicine and public health. ${ }^{3}$ This perspective may imply that population health and individual health are independent discrete concepts. However, one can also argue that the relationship between population and individual-based health is relative, dynamic, and should always be properly contextualized. ${ }^{4}$

With the macro-policy impact of the UHC Law that will change the service delivery landscape of the health system, critical analysis of the current scientific, legal, economic, and social evidence will provide objective policy development. Hence, for evidence-informed policymaking, the University of the Philippines Manila Health Policy Development Hub (UPM HPDH) in collaboration with the Department of Health, as the primary agency, conducted systematic research and a series of roundtable discussions to gather evidence as input in the Implementing Rules and Regulations (IRR) of the UHC Law. The DOH deliberated on the priority topics of the Law that call for policy research and stakeholders' discussion. This paper specifically analyzes the policy issue on establishing criteria for population- and individual-based health services, to efficiently delegate financing roles of PhilHealth and DOH.

\section{METHODS}

\section{Pre-work research}

A systematic review of literature was conducted to generate relevant information that can direct the discussion in the stakeholders' forum. This also served as input in crafting the policy brief presented in the forum. An electronic search of articles, reviews, related policies and researches on how to differentiate population-based and individual-based health services using PubMed database was done. In searching for the criteria for populationbased interventions, keywords used included "Population health" OR "Population-based services" OR "Populationbased intervention" OR "Population approach" AND "Universal Health Coverage" OR "Universal Health Care" which yielded 241 articles. For the criteria on individualbased interventions, the keywords used included "Individual health" OR "Individual-based services" OR "Individual approach to health" AND "Universal Health Coverage" OR "Universal Health Care" which yielded 321 articles. Articles were screened by titles, abstracts, and relevance, respectively yielding to 10 eligible articles, full text, published from 2004 to 2019 were included in the review.

To broaden the pool of literature, a Google Search using the abovementioned keywords was also conducted from the 
Table 1. Records per parameter of the study

\begin{tabular}{lll}
\multicolumn{1}{c}{ Parameter } & \multicolumn{1}{c}{ Details } & \multicolumn{1}{c}{ Frequency } \\
Current policies & Republic Act on government provision of quality free health services & 2 \\
\hline Population and individual health services & $\begin{array}{l}\text { DOH and PhilHealth covered health services, with overlapping provision. } \\
\text { Purchaser and provider roles should be clear. }\end{array}$ & 7 \\
\hline Health service utilization & $\begin{array}{l}\text { Supply and demand side on health service delivery should be considered in } \\
\text { determining the approach in provision, individual- or population-based }\end{array}$ \\
\hline Health service financing & $\begin{array}{l}\text { Fund allocation and utilization of health services across the continuum of care, } \\
\text { showing prioritization of budget. }\end{array}$ \\
\hline Total & & 5 \\
\hline
\end{tabular}

webpage of key institutions for supplementary documents. These yielded an additional four official reports, three online articles, one information page from the official website of PHIC, one PowerPoint presentation, and two laws. In total, 21 records, full text were included. Table 1 shows the number of full-text records included in the review.

The key points generated from the literature served as basis in formulating an algorithm proposed by the UPM HPDH in establishing criteria for population and individualbased health services, which was presented in the RTD. The synthesis of the systematic review of literature was used in crafting the policy brief presented in the roundtable discussion. Mainly this focused on the profile and the resources needed for the individual- and population-based services, the performance of the current set-up, and policy gaps. Below were the key findings of the literature review.

\section{Review of literature}

\section{A. Profile of Individual-based Services Financed by the $\mathrm{DOH}$}

As part of the Department of Health's effort to give equal health opportunity for primary care to all Filipinos, regardless of age, "Tamang Serbisyo sa Kalusugan ng Pamilya" (TSeKAP) was launched in 2015. TSeKAP is also the expanded version of PhilHealth's Primary Care Benefit (PCB) 1 and 2, which were implemented in 2012 and 2014, respectively. ${ }^{5,6}$ The TseKAP program delivers an essential package of health services which include: (a) Services these include complete physical examination, weighing of children, BP measurement, eye, ear, dental examination, breast examination, developmental assessment of infants, oral check-up, etc.; (b) Diagnostics - complete blood count, blood sugar testing, chest radiograph, sputum examination, urinalysis, fecalysis, etc.; and (c) Medicines/ commodities for ten common conditions that can be managed at the primary care level which include asthma, acute gastroenteritis, upper respiratory tract infection, diabetes mellitus, hypertension, dyslipidemia, deworming, and ischemic heart disease. ., $^{7,8}$ The abovementioned services can be considered individualbased services. Table 2 lists the services, diagnostics, and commodities/medicines financed by $\mathrm{DOH}$ and PhilHealth under the TSeKAP program. ${ }^{7}$
Outpatient services are classified under individual-based health services. Table 3 outlines commodities relevant to outpatient care that $\mathrm{DOH}$ finances and the corresponding services that have benefit packages from PhilHealth. ${ }^{7,8}$ It can be noted that immunizations for children and senior citizens are mostly funded by $\mathrm{DOH}$ and PhilHealth only has coverage for pneumococcal vaccines. Also, micronutrient supplementation has no corresponding package benefits from PhilHealth. The rest of the commodities (e.g. rabies, TB, malaria, deworming, HIV/AIDS, and non-communicable disease (NCD) medications, etc.) have corresponding benefit packages from PhilHealth.

\section{B. Performance in the Current Set-up}

Based on the literature review, funding or paying for services and commodities may refer to two important aspects: purchasing and procurement of goods. Purchasing refers to the process of transferring pooled funds to health service providers. Providers use these funds to deliver benefits to the population. ${ }^{9}$ Purchasing involves decisions on three aspects: (1) identifying interventions or services to be purchased, considering population needs, national health priorities, and cost-effectiveness; (2) choosing service providers, considering service quality, efficiency, and equity; (3) determining how services will be purchased, including contractual arrangements and provider payment mechanisms. ${ }^{7}$ On the other hand, procurement is the act of finding, acquiring, and buying of goods and services from an external source, often via tendering or a bidding process. ${ }^{7}$

In the Philippine context, as stated in Republic Act 7875, Article III, PhilHealth is limited to "paying for health services for covered beneficiaries or to purchasing health services..." on behalf of their beneficiaries. It is prohibited from (i) buying and dispensing drugs and pharmaceuticals, (ii) providing health care directly, and (iii) from owning or investing in health care facilities. ${ }^{10}$ On the other hand, the Department of Health holds the role of procurement for health programs. In the current set up, there is an overlap of health service provision by $\mathrm{DOH}$ and PhilHealth (Tables 2 and 3). It is important to avoid overlap in financing roles as it dilutes the purchasing power, which subsequently weakens the government's capacity to control the behavior of providers and to decrease the cost of goods and services. Other disadvantages of overlap include perpetuation of 
Population- and Individual-based Health Services

Table 2. List of Services, Diagnostics, and Medicines/ Commodities financed by the Department of Health and PhilHealth ${ }^{7}$

\begin{tabular}{|c|c|c|}
\hline & DOH TSeKAP & PhilHealth (Primary Care Benefit Package) \\
\hline $\begin{array}{l}\text { Preventive } \\
\text { Services }\end{array}$ & $\begin{array}{l}\text { BP Measurement } \\
\text { Breast Examinations } \\
\text { Visual Inspection with Acetic Acid } \\
\text { Body Measurement (Ht and Wt. Measurement) } \\
\text { Dental Check-Up } \\
\text { Referral Service to Higher Level of Care }\end{array}$ & $\begin{array}{l}\text { Consultation } \\
\text { BP Measurement } \\
\text { Breast Examinations } \\
\text { Visual Inspection with Acetic Acid } \\
\text { Body Measurement } \\
\text { Risk Profiling for Hypertension (HTN) and Diabetes Mellitus (DM) } \\
\text { Oral check-up and prophylaxis for children }\end{array}$ \\
\hline Diagnostics & $\begin{array}{l}\text { Complete Blood Count } \\
\text { Urinalysis } \\
\text { Chest x-ray } \\
\text { Blood sugar }\end{array}$ & $\begin{array}{l}\text { Complete Blood Count } \\
\text { Urinalysis } \\
\text { Fecalysis } \\
\text { Sputum Microscopy } \\
\text { Fasting Blood Sugar } \\
\text { Lipid Profile } \\
\text { Chest X-ray } \\
\text { Electrocardiogram } \\
\text { Peak expiratory flow meter testing } \\
\text { Glucometer }\end{array}$ \\
\hline $\begin{array}{l}\text { Drugs and } \\
\text { Medicines }\end{array}$ & $\begin{array}{l}\text { Drugs and Medicines for Chronic Conditions } \\
\text { (Hypertension, Diabetes) } \\
\text { Medicines for TB and Malaria }\end{array}$ & $\begin{array}{l}\text { Asthma: SABAs, ICS, OCS* } \\
\text { Acute Gastroenteritis: Oral Rehydration Solution } \\
\text { Upper Respiratory Tract Infection/Pneumonia: Amoxicillin, Erythromycin } \\
\text { Urinary Tract Infection: Fluoroquinolones } \\
\text { HTN Medications } \\
\text { DM Medications } \\
\text { Dyslipidemia Medications } \\
\text { Deworming Medications } \\
\text { Ischemic Heart Disease Medications }\end{array}$ \\
\hline
\end{tabular}

${ }^{*}$ short-acting beta2-agonist (SABA) Inhaled corticosteroids (ICS) Oral corticosteroid (OCS)

Table 3. Commodities financed by DOH and the corresponding Outpatient Benefit Packages from PhilHealth ${ }^{7}$

\begin{tabular}{ll}
\multicolumn{1}{c}{ DOH } & \multicolumn{1}{c}{ PhilHealth } \\
Immunization Commodities for Infants, Adolescents, and Senior Citizens & Pneumococcal Vaccines \\
Family Planning Commodities & Voluntary Surgical Contraception Procedures \\
Micronutrient Supplementation & - \\
Rabies Dx and Vaccines & Animal Bite Treatment Package \\
NCD Medications (DM, HTN, and Dyslipidemia) & NCD Medications Part of TSeKaP \\
Deworming Medications & Deworming Medications Part of TSeKaP \\
Tuberculosis (TB) Medicines & Outpatient TB Package \\
HIV/AIDS Medicines & Outpatient HIV Package \\
Medicines for Malaria & Outpatient Malaria Package \\
\hline
\end{tabular}

fragmentation in the health system, unnecessary duplication of human resources, and confusion of beneficiaries on where to access specific healthcare services. ${ }^{7}$

\section{Resources Needed to Deliver Population-Based Health Services}

Population-based information includes data on "prevalent health problems, health risks within the community and preventive services for particular patient groups" while population-based health strategies include "community-wide screening, case finding and outreach programs." In general, the population health approach focuses on the health and overall well-being of the population it serves. These include public efforts, in complement with clinical care, that provides a comprehensive set of promotive, preventive and curative health services that promote overall population health. These services may include but are not limited to: prevention and control of infectious diseases (e.g. tuberculosis [TB], malaria, schistosomiasis, dengue, rabies, human immunodeficiency virus $[\mathrm{HIV}]$, and acquired immunodeficiency syndrome [AIDS], etc.), diagnosis and treatment of communicable diseases, prevention and control of non-communicable diseases (NCD), maternal and neonatal care, tobacco control, violence prevention, and food safety. ${ }^{11}$

The Department of Health Budget Report in 2018 indicated that based on the continuum of care, preventive and promotive healthcare had the highest share of funds (38\%, PhP 40.75B) which included health promotion, $\mathrm{HRH}$ deployment, and public health management. A significant portion $(50 \%, \mathrm{PhP} 53.07 \mathrm{~B})$ went to curative health care which included operations and upgrading of $\mathrm{DOH}$ and local government hospitals (Figure 1). ${ }^{12}$

On the public health / preventive care funds, national immunization had the largest contribution amounting to PhP 7.44 billion, followed by 'family health, nutrition, and responsible parenting' with $\mathrm{PhP} 3.64$ billion allocations 
Php 12.26 B

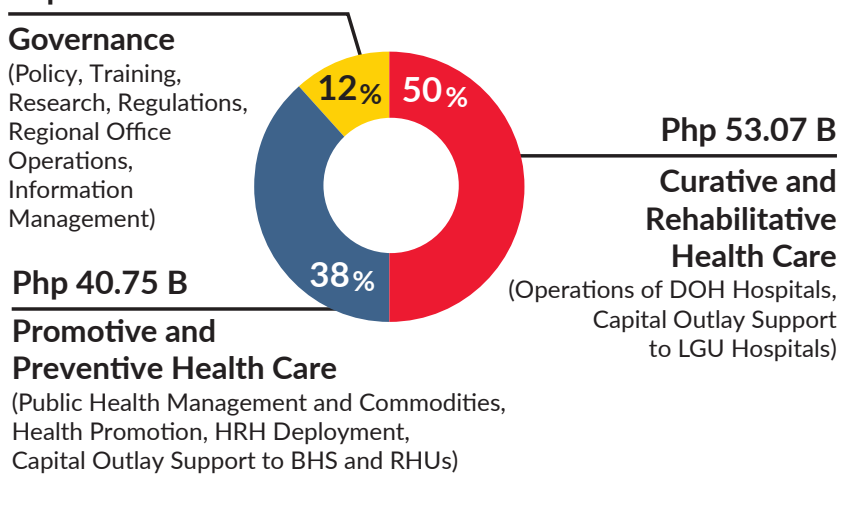

a Computed as GAA 2018 DOH \& Philhealth budget level minus GAA 2013 DOH Budget level

Figure 1. DOH budget (PhP 106.08B) based on Continuum of Care in $2018 .{ }^{12}$

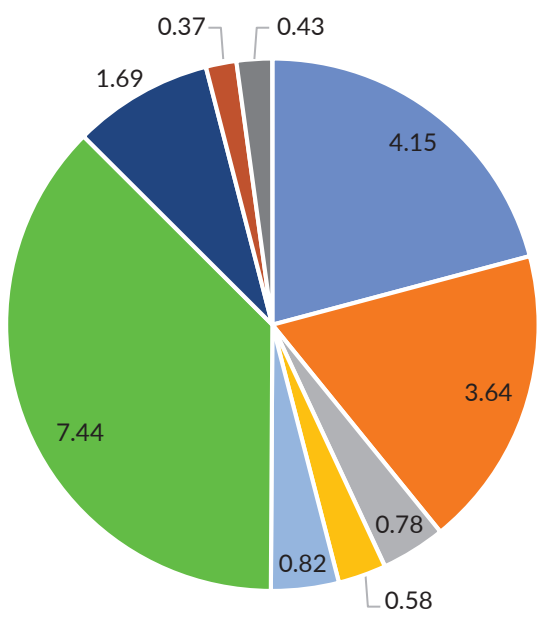

- Public Health Management

- Family health, nutrition, and responsible parenting

- TB Control

- Rabies Control

- Operation of Dangerous Drug Abuse and Rehabilitation Centers

- National Immunization

- Prevention and Control of Other Infectious Diseases

- Elimination of Diseases

- Prevention and Control of NCDs

Figure 2. DOH major program allocations of $\mathrm{MOOE}$ and $\mathrm{CO}$ in Public Health Programs (in billion PhP).

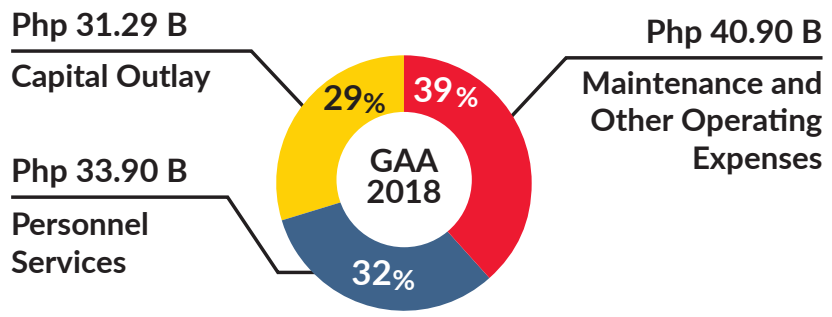

Figure 3. DOH budget in 2018 based on Expense Class. ${ }^{12}$
(Figure 2). ${ }^{12}$ This illustrates how the budget was allocated mostly to population-based services.

Based on the expense class, the highest allocation of the budget was on maintenance and other operating expenses (MOOE) with 39\% (PhP 49.9B), followed by 32\% (PhP 33.91B) for personnel services (PS), and 22\% (PhP 31.29B) for capital outlay $(\mathrm{CO})$ (Figure 3). ${ }^{12}$ It is also noted that budget allocation across all expense class increased from the previous year, with the highest increase noted in PS (21\%), equivalent to 5.9 billion. This is mainly attributed to the third tranche increase of salary as per Salary Standardization Law of 2015.12 Magnifying the budget utilization, the obligation rate was $94 \%$, but the disbursement rate over total allotment was $60 \%$ only due to low disbursement in MOOE and CO expense. ${ }^{12,13}$

There is no clear delineation as to what resource or expense class contributes directly to the individual or population-based services. It is also important to note that a significant proportion of the budget allocated to MOOE and $\mathrm{CO}$ was not fully utilized which might be influenced by the financial absorptive capacity of the agencies. Hence, costefficiency of budget allocation and utilization might need to be revisited, especially with the transition to cash-based budgeting system within the fiscal year.

\section{Conduct of Policy Roundtable Discussion}

The UP Manila Health Policy Development Hub (UPM HPDH) as the research agency, together with the Department of Health, as the primary agency, conducted a roundtable discussion participated by key representatives from the national government agencies, local government units, private societies, academe, and non-government organizations to share insights and evidence identified related aspects of health service delivery and health financing,

The ultimate goal of the policy RTD was to reach a consensus on policy recommendations regarding what will be considered population-based and individual-based health services. To provide common background knowledge on the policy issue, a Policy Hub member presented the policy brief, highlighting the past and present policies for improving health service delivery by DOH and PHIC. Further, the proposed algorithm was presented to elicit insights and gather suggestions for improvement. This opened the issues on gaps in the financial coverage of PhilHealth and how the UHC law intends to address these. Participants' understanding of the policy issue was further strengthened by the key resource speakers from national agencies. A representative from PHIC gave an overview of the current system of NHIP financial coverage of health services, costing initiatives, timeline, and roadmap towards shifting Disease-Related Groups-Global Budget (DRG-GB). For ground experience, a former Secretary of Health gave an overview of the current health situation in a municipality in Eastern Samar, a geographically isolated and disadvantaged area (GIDA). The barriers in health service delivery in 
challenged areas were identified including but not limited to absence or lack of health human resource in underserved areas despite the availability of health infrastructures and PhilHealth coverage.

Based on the deliberation of the research team (UPM $\mathrm{HDPH}$ ) and primary agency (DOH), specific questions that the RTD aimed to answer were as follows:

1. What are the strengths and weaknesses in the current service delivery network (SDN) concerning financing roles of DOH, PhilHealth, LGUs?

2. What emerging, good, and best practices can be drawn or considered?

3. Based on the UHC Act definition and the identified strengths and weakness of SDN, what criteria should be established in identifying population- and individualbased health services?

Thematic analysis of the policy discussion was organized based on the discussion questions. In crafting the policy paper, both reviews of literature and policy discussion were utilized. To attain consensus in the policy recommendations, the draft was circulated to all RTD participants for their inputs. The policy paper was revised as necessary.

\section{RESULTS AND DISCUSSION}

\section{Strengths and Weaknesses of the Current Service Delivery Networks (SDNs)}

In assessing the performance of the current set-up of financing, the strengths and weaknesses of the service delivery networks were discussed during the roundtable discussion to determine gaps and propose mitigating measures.

\section{Strengths of the current SDNs}

Local Health Boards are already in place as previously decreed through RA 7160, otherwise known as the Local Government Code of 1991. However, participants shared that RA 7160 gave rise to challenges in health program development and management system among the local chief executives who have the fiscal autonomy in the formation of trust funds exclusively for health care. With the UHC Act strengthening the role of Provincial Health Board in appropriating funds for health services, the politicallycharged question that begs for a pragmatic answer is, what would be the reliable mechanism to ensure that all local chief executives (LCEs) will support equitable service provision, even those with no inclination to health? Thus, the role and the implementation of the Local Health Boards in the LGUs should be revisited and re-examined. It is imperative to determine its composition, as all relevant stakeholders from different sectors including government, private, NGOs, patient advocate groups, and others, should be well represented to maximize function potential.

Though the health trust fund is already in place, there is a need to review the gaps given its nature. It was discussed that the change in roles or allocation of funds will largely depend on how strong the governance and accountability of the local government units will be. In transitioning to the provincelevel integration, the local chief executives must have the strong inclination and support the equitable provision of health care services while protecting its constituents from financial risks. Competencies development is needed to mold leaders that are congruous with the aim of the UHC law.

Based on the UHC Act, the decision on allocating health funds comes from provincial or local health boards, which are local enterprises that are juridical at the provincial level. The local government units can form these enterprises given compliance to certain requirements. To mitigate political biases, decision making should be evidence-based, supported by strengthened health information system.

\section{Weaknesses of the current SDNs}

The participants agreed that the lack of an electronic database or registry at the LGU level deters decision-makers in making evidence-informed decisions on how SDNs may be better financed. Gaps in the data of the private sector were noted. Some of these include poor implementation of disease reporting and infrequent inclusion of reports from the private sector in the local database. These are crucial in obtaining the actual statistics of diseases. Therefore, noncompliance with health facilities to reporting shall be penalized accordingly.

The participants also recognized that PhilHealth is a major player in health financing but the benefits are not maximized by the members and the Filipino population, in general. In particular, benefits are only available at a certain level and not as accessible as subsequent availments. This is further compounded by the lack of awareness of patients on the benefits they are entitled to and their procedures in availing them. Also, coverage is mainly for inpatient services while only to a limited extent for outpatient services. To improve accessibility and quality in healthcare, patient navigators should also be engaged in the health system..$^{11,12}$

The discussion also emphasized the distinction between the source of health funds based on the current law and the UHC law which are facility-based and network-based, respectively. As the UHC law implements a networkbased trust fund, private health providers will need to join networks to adapt to the new health system. As argued by the $\mathrm{HMO}$ representative, financing this initiative involves the HMO industry that contributes to around $3 \%$ of the health expenditures of Filipinos in general, but has high market shares in specific subgroup populations (e.g. corporate employees, higher-income group, etc.).

\section{Criteria for population-based and individual-based health services}

In the roundtable discussion, as far as PhilHealth (PHIC) is concerned, health services with All Case Rates (ACR) and those that are reimbursable through the proposed payment 
mechanism of DRG-GB are individual-based. Similarly, HMO services are also considered individual-based.

During the discussion, representatives from professional societies and hospital organizations raised concerns on the interpretation of individual-based services as defined in the UHC Act, which pertains to services that "do not alter the underlying cause of illness." The statement is vague and thus leads to certain 'grey areas.' According to some participants, this may be interpreted differently by physicians or health care providers; technically, any intervention or service directed to individuals may alter the underlying cause of illness. Other examples of grey areas as identified by the participants were as follows:

\section{Tuberculosis (TB)}

- TB Control/outpatient services - currently funded by DOH. Should it be population- or individual-based?

- If the doctor advised a patient to have specific TB diagnostics and take medications - these then become individual-based services. Who shall fund these?

\section{Vaccinations}

- If it is a service that the client is paying for, then the service has an individual-based component

- Drug deliveries, promotion and campaigns, and supply chain are the population-based components

Several proposals were raised in the discussion on how to address grey areas:

1. Any grey area health services shall be funded by $\mathrm{DOH}$.

2. All grey areas health programs should be identified and discussed in the IRR so that the components (promotion, prevention, curative, and palliative) of each grey area that will be either individual- or population-based services will be defined and subsequently be funded by PhilHealth or DOH, respectively.

3. Clarification of grey areas should be subjected to a technical working group.

A proposed outcome-based algorithm in classifying $\mathrm{DOH}$ programs into population-based or individual-based services is shown in Figure 4.

For DOH health programs (e.g. TB-DOTS, malaria, EPI, etc.), failure to reach the target outcome could be traced to fragmentation issues in service delivery. It could be in the poor demand generation where despite the availability and accessibility of equitable and quality health services of a program, utilization remained low due to the socio-cultural and geographical determinants. Hence, there might be a need to change the design of service delivery to individual-based service provision, catering to the need of the target segment of the population. These should address the aforementioned factors that hinder service utilization.

Much of literature focused on the supply side of service delivery, and paucity of evidence is noted on the demand side to generate diverse research findings that would aid in contextualizing strategic approaches of service delivery across varying cultural, socio-demographics, and geographical accessibility of the population. ${ }^{14}$ Demand-side refers to the "behavior and inputs of the recipients or intended recipients of these efforts: individuals, households, and communities." ${ }^{15}$ Operational and policy perspectives on the demand side of service delivery have raised policy reforms with the shift of locus of intervention, particularly on low- to middle-income countries with a pro-poor agenda approach. ${ }^{14,15,16}$ Some of the identified determinants of health-seeking behavior that

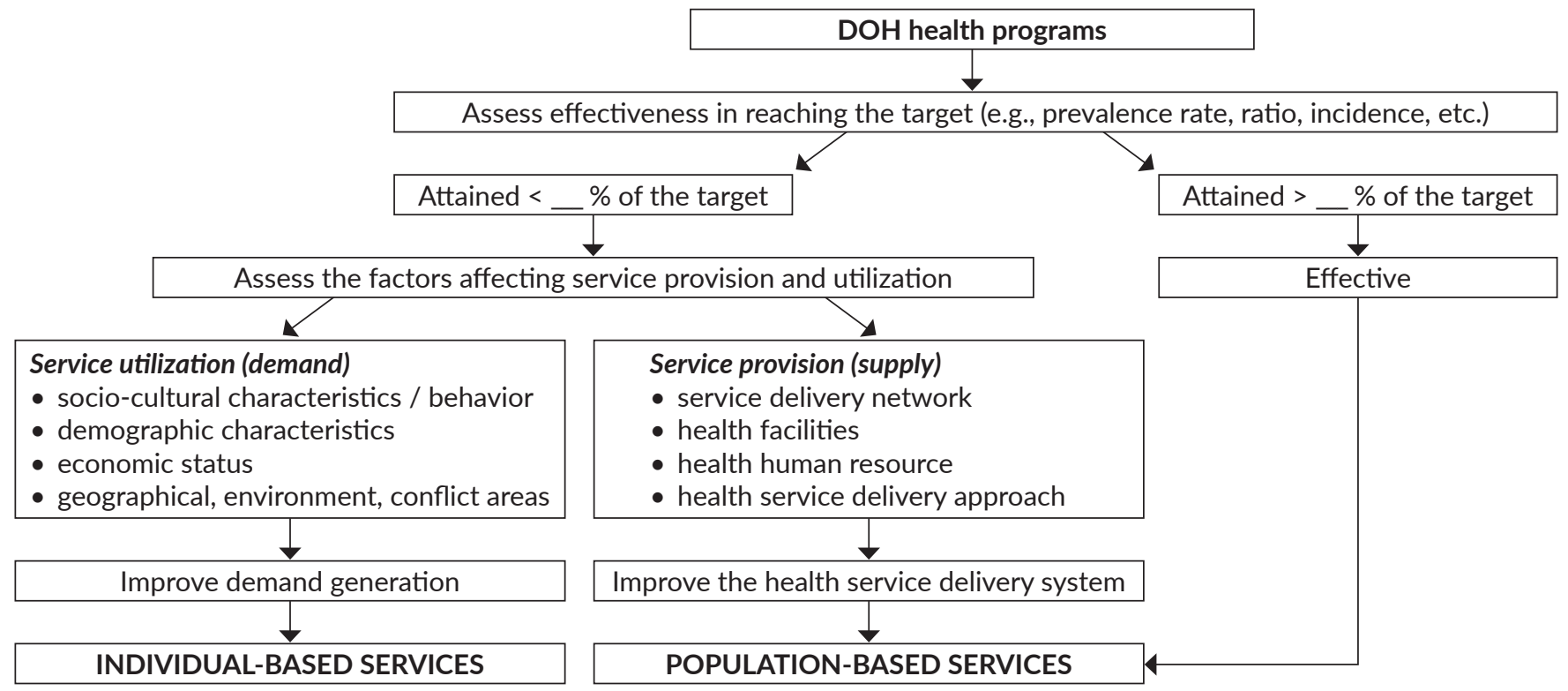

Figure 4. UPM HPDH proposed an algorithm in classifying DOH health programs into population-based and individualbased services. 
acts as barriers are poor education, cost of health service, household roles as associated to the opportunity cost of seeking care, and lack of basic knowledge on health services availability and accessibility, among others. ${ }^{14,15}$ Studies showed that socio-cultural factors and gender have been evident determinants of health service utilization wherein females were shown to demonstrate lower or delayed health seeking-behavior while men value quality medical care. ${ }^{17-20}$ One of the commonly identified approaches is to develop social accountability which focused on the productive participation of the society and the State in pursuit of a shared goal. This entices mobilization of stakeholders that brings forth collective action; hence, responsive service delivery is created. ${ }^{15,16}$

As for the Philippines, the literature showed that access to health care services has always been challenging despite the presence of a working network of health facilities such as barangay health stations, municipal and city health centers, and public and private hospitals. For instance, mothers belonging to the lowest income quintile delivered at home and were attended only by traditional birth attendants instead of doctors. Identified barriers were the cost of treatment, unavailability of drugs, the distance of health facility, inaccessibility of transportation, and lack of available providers, among others. ${ }^{21}$ With the focus of the UHC Law on the provision of quality, affordable, and accessible services for all Filipinos, addressing the challenges in the demand side would mitigate inequities in health services.

On the other hand, the algorithm illustrates that if the gap is identified in the supply side such as unavailability and inaccessibility of health services of a program due to fragmented SDNs, inadequate or poor health infrastructure, health human resource, and service delivery approach, then there is a need to improve health service delivery system as a population-based service. Investments must then be prioritized in these areas not only in funding but also in capacity building of health workforce as deemed necessary.

It is instructive to appreciate that:

1. The same outcome-based problems may yield different types of information due to diverse local level conditions or settings.

2. Outcome inadequacies whose underlying causes are services or facility/ structural-based are normally better addressed through population-based interventions; while individual decision-related causes are better addressed through individual-based interventions. Meanwhile, sociocultural-related causes are better addressed by a combination of population-based interventions (e.g. IEC program) complemented by an individual-based intervention (e.g. incentives for accessing).

3. To minimize disruptions, $\mathrm{DOH}$ health programs that are successful, should remain with $\mathrm{DOH}$ as de facto population-based services, unsuccessful health programs whose key solutions are individual-based should be transferred to PHIC, and unsuccessful health programs whose key solutions are population-based should remain as population-based services. Meanwhile, unsuccessful health programs whose key solutions are a mixture with no clear majority (grey area) may be tackled by a joint DOH-PHIC body.

\section{CONCLUSION AND RECOMMENDATIONS}

Identifying health services as population-based or individual-based is fundamental in delegating responsibilities and allocating funds from key agencies such as $\mathrm{DOH}$ and PhilHealth in the implementation of the UHC Act.

In rationalizing the definition of the individual-based services in the UHC Act, it was recommended that these services be those with All Case Rates reimbursable through PhilHealth and Disease-Related Groups-Global Budget and those covered by HMOs. Meanwhile, health services that will benefit population groups were suggested to be funded by the Department of Health. During the discussion, there were identified services under grey areas, such as services provided at the population level but have individualized approach in provision depending on the characteristics of the disease and the profile of the patient. As such, it is instructive to examine the health outcomes vis a vis the health service delivery to determine and subsequently address the fragmentation caused by either the service provision (supply) or service utilization (demand).

\section{Statement of Authorship}

All authors participated in data collection and analysis, and approved the final version submitted.

\section{Author Disclosure}

The authors declare no conflicts of interest.

\section{Funding Source} HPSR.

This project was funded by the DOST DOH AHEAD-

\section{REFERENCES}

1. Republic of the Philippines. Republic Act 11223. An Act Instituting Universal Health Care for All Filipinos, Prescribing Reforms in the Health Care System Amending for The Purpose Certain Laws, Appropriating Funds Therefore and for Other Purposes; 2018.

2. Cohen D, Huynh T, Sebold A, Harvey J, Neudorf C, Brown A. The population health approach: a qualitative study of conceptual and operational definitions for leaders in Canadian healthcare. SAGE Open Med. 2014 Feb; 2:2050312114522618. doi: 10.1177/2050312114522618.

3. Conceptual Basis for Prevention and Control of Non-communicable Diseases [Internet]. n.d. [cited 2019 Sep]. Available from: https:// www.dh.gov.hk/english/pub_rec/pub_rec_ar/pdf/ncd/chap_2.pdf.

4. Arah OA. On the relationship between individual and population health. Med Health Care Philos. 2009 Aug; 12(3):235-44. doi: 10.1007/s11019-008-9173-8.

5. Mocon-Ciriaco C. TSEKAP campaign serves thousands of Pinoys [Internet]. 2016 [cited 2018 Oct 20]. Available from: https:// 
businessmirror.com.ph/tsekap-campaign-serves-thousands-ofpinoys/.

6. David LC, Gonzales RG, Elgo- Mamaril FR, Narido-Magbanua E, Manalo WJC, Alde GAP. Annual Report 2015. Manila, Philippines: Health Policy Development and Planning Bureau- Department of Health [Internet]. 2016 [cited 2018 Oct 20]. Available from: https:// www.doh.gov.ph/sites/default/files/publications/DOH_Annual_ Report_2015_07132016.compressed.pdf.

7. All Life Stages Technical Working Group. Primary Health Care Entitlements of Filipinos [PowerPoint Slides]. 2016.

8. Philippine Health Insurance Corporation. Benefits [Internet]. 2018 [cited 2018 Nov 26]. Available from: https://www.philhealth.gov. $\mathrm{ph} /$ benefits/.

9. World Health Organization. Purchasing and provider payment systems [Internet]. n.d. [cited 2018 Nov 17]. Available from: http:// www.who.int/health_financing/topics/purchasing/en/.

10. National Health Insurance Act of 1995, Republic Act No. 7875. February 14, 1995.

11. Shahzad M, Upshur R, Donnelly P, Bharmal A, Wei X, Feng P, et al. A population-based approach to integrated healthcare delivery: a scoping review of clinical care and public health collaboration. BMC Public Health. 2019 Jun; 19(1):708. doi: 10.1186/s12889-019-7002-z.

12. DOH Budget Brochure 2018 [Internet]. [cited 2019 Dec 12]. Available from: https://www.doh.gov.ph/node/12944.

13. Villaverde M, Beltran M, Mamaril FR. Department of Health Annual Report 2018. Manila, Philippines: Health Policy Development and Planning Bureau-Department of Health.
14. Esnor T, Cooper S. Overcoming barriers to health service access: influencing the demand side. Health Policy Plan. 2004 Mar; 19(2): 69-79. doi: 10.1093/heapol/czh009.

15. Standing Hillary. Health Systems Resource Centre. Understanding the "demand side" in service delivery: Definitions, frameworks and tools from the health sector. University of Sussex. 2004.

16. Joshi A. Producing Social Accountability? The Impact of service delivery reforms. IDS Bull. 2008 Jan; 38(6):10-7.

17. Das M, Angeli F, Krumeich AJSM, van Schayck OCP. The gendered experience with respect to health-seeking behaviour in an urban slum of Kolkata, India. Int J Equity Health. 2018 Feb; 17(1):24. doi.org/10.1186/s12939-018-0738-8.

18. Ahmed SM, Adams AM, Chowdhury M, Bhuiya A. Changing health-seeking behaviour in Matlab, Bangladesh: do development interventions matter? Health Policy Plan. 2003 Sep; 18(3):306-15. doi: $10.1093 / \mathrm{heapol} / \mathrm{czg} 037$.

19. Smith A, Burger R., Claassens M, Ayles H, Godfrey-Faussett P, Beyers N. Health care workers' gender bias in testing could contribute to missed tuberculosis among women in South Africa. Int J Tuberc Lung Dis. 2016 Mar; 20(3):350-6. doi: 10.5588/ijtld.15.0312.

20. Bertakis KD, Azari R, Helms LJ, Callahan EJ, Robbins JA. Gender differences in the utilization of health care services. J Fam Pract. 2000 Feb; 49(2):147-52.

21. Paterno RP. The future of universal health coverage: a Philippine perspective. Glob Health Gov. 2013; VI(2):1-21. 